\title{
Bailouts and the Optimal Taxation of Bonus Pay
}

\author{
By Timothy Besley and Maitreesh GhataK*
}

Little undermines the case for a market economy more than the perception that there is injustice in the rewards that it generates. In that sense, the recent financial crisis is a body blow, and has spawned a series of noisy but so far largely ineffectual campaigns for radical change from the Left (e.g., the Occupy Wall Street movement). But the greatest clamor for reform should come from those who support the market system. When push came to shove, it was the government that came to the rescue of financial institutions and public money that proved to be the cornerstone of the financial system. And there is a more than respectable case that a sizeable transfer of resources from public to private hands have enriched workers in the financial sector at the expense of citizens at large. And this is put into sharp relief by the observation that a good deal of the increase in inequality that has been seen in recent years is due to bonus pay in the financial sector and beyond see Brian Bell and John Van Reenen (2010) and Thomas Lemieux, W. Bentley MacLeod, and Daniel Parent (2009).

At the same time, and partly in response to the financial crisis and its fiscal consequences, societies are revisiting the question of how the rich should be taxed. The rules of the game in advanced democracies have evolved to view the tax system as the primary legitimate source of redistribution. Broad-based progressive income tax systems are central to this and are seen as a fair and equitable way of paying for transfer programs and public services. But the question of whether and how the tax system should differentiate by source of income is not clear. For both practical and theoretical reasons, taxes on income from capital are structured differently from taxes on labor earnings. And bonus pay,

\footnotetext{
* Besley: LSE, Houghton Street, London WC2A 2AE, UK, t.besley@1se.ac.uk. Ghatak: LSE, Houghton Street, London WC2A 2AE, UK, m.ghatak@1se.ac.uk. An earlier version of this paper was circulated under the title "Taxation and Regulation of Bonus Pay" (Besley and Ghatak, 2011). We are grateful to Abhijit Banerjee, Konrad Burchardi, Rocco Macchiavello, John Vickers, and several seminar audiences for helpful feedback.
}

to the extent that it is taxing a risky return (to labor effort or risk taking), has some similar features. The classical optimal tax model due to James A. Mirrlees (1971) has focused on taxing returns to ability. But there is some recent interest in taxing rents - see Casey Rothschild and Florian Scheuer (2011). Here we show that the possibility of bailouts to financial intermediaries distorts the supply price of capital and creates an argument for taxing financial bonuses separately from other sources of income. The taxes that we propose increase both equity and efficiency compared to the pure market outcome. ${ }^{1}$

\section{Analysis \\ A. The Model}

We employ a very simple equilibrium model of financial intermediation with moral hazard with respect to both effort and risk-taking to make the main points of interest - see Jean Tirole (2006), chapter 7 , for a review of related models in the corporate finance literature. Intermediaries compete to employ workers who choose investment projects and raise funds for these projects from investors in competitive capital markets. There are three groups of citizens. For simplicity, membership of each group is mutually exclusive. There are $M>1$ consumers each of whom has an endowment 1 unit of capital. The economy comprises $N$ financial intermediaries and $n$ potential financial sector workers. Each financial intermediary can hire at most one financial sector worker. Each agent can manage one unit of capital. We assume that $M>N>n$ so that capital is not scarce but skilled agents are. This assumption will imply that any rents to financial intermediation accrue to financial sector workers. ${ }^{2}$ Neither intermediaries nor financial workers have any wealth that

\footnotetext{
${ }^{1}$ See Roland Benabou and Jean Tirole (2012) for a related argument based on competition and heterogeneous talent in a multi-tasking setting.

${ }^{2}$ An upward sloping supply of financial sector works would see the gains distributed between owners of firms and workers.
} 
can be posted as a performance bond and their payoffs are subject to a limited liability constraint. Everyone, including consumers, is risk neutral. Consumers have access to a safe asset which yields a gross return of $\rho>1$. This implies that there is a perfectly elastic supply of $M$ units of capital as long as intermediaries pay an expected return of $\rho$.

Financial intermediaries invest in risky projects. There are three states of the world $s \in\{L, M, H\}$ with corresponding returns: $\Pi_{H}>\Pi_{M}>\rho>\Pi_{L}=0$. The likelihood of the realization of these returns is affected by the actions of financial sector workers. These can be thought of concretely as decisions about which projects to invest in. There are two dimensions of choice: productive effort $e \in[\underline{e}, 1]$ and risk-taking effort $r \in[0, \bar{r}]$ where $\underline{e}>0$ and $\bar{r}<1$.

Effort increases investment returns in the sense of first order stochastic dominance while the choice of $r$ transfers probability mass away from the middle return towards the high and low returns. We use a technology which is additively separable in risk-taking and effort. Specifically, Let $p_{s}(e, r)$ denote the probability that the return is $s$. Then, the probability distribution over investment returns is as follows:

$$
\begin{aligned}
p_{H}(e, r) & =\alpha e+\beta r \\
p_{M}(e, r) & =(1-\alpha) e-r \\
p_{L}(e, r) & =(1-e)+(1-\beta) r
\end{aligned}
$$

where $\alpha \in(0,1), \beta \in(0,1)$ and $\alpha+\beta<1$. We also assume that $(1-\alpha) \underline{e}-\bar{r}>0$ which implies that $1>(1-\underline{e})+(1-\beta) \bar{r}$. Thus, for any choice of $e$ and $r$, all three states occur with positive probability.

The cost to the intermediary of choosing $(e, r)$ is assumed to be quadratic and additively separable: $C(e, r)=\frac{1}{2} e^{2}+\frac{1}{2} r^{2}$. This implies that the agent has to seek out risk-taking opportunities at a cost to himself and without any incentives, will not take any risks. ${ }^{3}$

To attract capital, a financial intermediary pays a contractual return of $R$ to investors if it

\footnotetext{
${ }^{3}$ It would be straightforward to extend the model to introduce a "normal" or "benchmark" level of risk taking $\hat{r}>0$ and to suppose that it is costly to deviate from that level. In this case the cost of risk-taking effort would be $\frac{1}{2}(r-\hat{r})^{2}$.
}

makes a positive profit. ${ }^{4}$ Since no cash returns are generated when the state is $L$, there is no option to offer a return in this case. However, we assume that the government may bail out the investor in such cases, and offer a return of $\rho$. For simplicity, we assume that the bailout decision is a binary one: $x \in\{0, \rho\}$. Given that capital is not scarce, the intermediary has to offer an expected return of only $\rho$. This implies that the intermediary can set $R=\rho$ and still attract capital.

We focus on the simplest form of public finance with bailouts being financed by lumpsum taxes levied on consumers. In this case, the per capita tax needed to finance expected losses is: $T=[1-e+(1-\beta) r] \rho$. Define $A(x)=\alpha \Pi_{H}+(1-\alpha) \Pi_{M}-x$ and $B(x)=$ $\beta \Pi_{H}+(1-\beta) x-\Pi_{M}$ We make the following four-part assumption:

Assumption: (i) $\frac{1}{4}\left\{A(x)^{2}+B(x)^{2}\right\}>\rho$; (ii) $\Pi_{M} \geq \frac{\rho}{\underline{e}-(1-\beta) \bar{r}}$; (iii) $B(0)=0$; (iv) $1>A(0)$ and $\bar{r}>B(\rho)$.

These assumptions ensure that: risky projects are profitable ex ante with or without bailouts; even without a bailout, the intermediary can credibly promise a sufficient return to the investor to compensate him for risk for any choice of $e$ and $r$; greater risk-taking, in the absence of a bailout, generates a purely mean-preserving spread in returns, and in particular, the parameter restriction $\beta \Pi_{H}=\Pi_{M}$; solutions are interior for $x \in\{0, \rho\}$. The workers receive a state-contingent wage $\left\{w_{H}, w_{M}, w_{L}\right\}$ whose structure determines the extent to which incentives are high-powered. The fact that the intermediary has no cash when the state is $L$, since the bailout is used to compensate investors, implies that $w_{L}=0$.

\section{B. Socially Optimal Bonus Pay}

An optimal second best financial contract is a pair $\left\{w_{H}, w_{M}\right\}$ that maximizes the principal's payoff subject to limited liability, the incentivecompatibility constraints (ICs), and the agent's participation constraint (PC). The agent's expected payoff is $e\left\{\alpha w_{H}+(1-\alpha) w_{M}\right\}+$

\footnotetext{
${ }^{4}$ The profit level is observable to the intermediary, enabling profit-contingent remuneration, but not effort or risk. Investors however can only observe if there was positive profit or not, so that only debt contracts are feasible.
} 
$r\left\{\beta w_{H}-w_{M}\right\}-\frac{1}{2} e^{2}-\frac{1}{2} r^{2}$. The ICs are found by maximizing the agent's payoff and are:

$$
\begin{aligned}
e & =\alpha w_{H}+(1-\alpha) w_{M} \\
r & =\beta w_{H}-w_{M} .
\end{aligned}
$$

To find the efficient combination of effort and risk-taking for fixed $u$, we use the the incentive constraints (2), and define $\hat{S}(x, u)$ as the solution to

$$
\max _{e, r}\{e[A(x)-e]+r[B(x)-r]-\rho\}
$$

subject to $\frac{1}{2} e^{2}+\frac{1}{2} r^{2} \geq u$ (which is obtained by substituting the ICs in the agent's PC). The distributional decision then solves for the utility of financial sector workers, $u$, given the welfare weight $\lambda$ which is given by: $\hat{u}=\arg \max _{u \geq \underline{u}}\{\hat{S}(0, u)+\lambda u\}$. The solution to this two-stage problem is straightforward and is given in: ${ }^{5}$

PROPOSITION 1: Socially optimal incentives are high powered to provide effort incentives but are set to avoid risk-taking. Specifically:

$$
\begin{aligned}
w_{H}^{*} & =\frac{1}{2-\lambda} \frac{A(0)}{\alpha+\beta(1-\alpha)} \\
w_{M}^{*} & =\frac{1}{2-\lambda} \frac{\beta A(0)}{\alpha+\beta(1-\alpha)}
\end{aligned}
$$

with effort and risk-taking choices being: $e=$ $\frac{A(0)}{2-\lambda}$ and $r=0$.

Four features of this solution are worth noting: (i) incentives are set to avoid risk-taking since $\beta w_{H}^{*}=w_{M}^{*}$. (ii) incentives are high powered with $w_{H}^{*}>w_{M}^{*}>0$. (iii) The level of incentive pay is increasing $\lambda$ which is the social value attached to rewards in the financial sector. Incentive pay is lowest when $\lambda=0$ when the planner attaches no weight to the utility of financial sector workers. However, the latter continue to earn a rent (namely, the participation constraint does not bind and so they earn the utility equivalent of efficiency wages) on account of the need to incentivize them. (iv) the solution for bonus pay does not depend on $x$. This is because the bailout is a transfer and its level does not matter

\footnotetext{
${ }^{5}$ The proof of this and subsequent results are in the appendix.
}

in the second best optimum where incentives are set by a social planner.

\section{The Market Outcome}

In a market setting, financial intermediaries compete by offering wage contracts to workers. These contracts respect the fact that effort and risk-taking are not directly contractible. However, intermediaries will ignore the effect of their behavior on expected bailout costs, thereby creating a divergence between the socially optimal bonus structure and the market determined outcome. Since we have assumed that financial sector workers are scarce, all of the surplus will go to them, i.e. $\hat{S}\left(\rho, u^{*}(\rho)\right)=0$ where $u^{*}(\rho)$ is the market determined utility level of a financial sector worker when the bailout is $x$. As long as there are values of $w_{H} \in\left[0, \Pi_{H}\right]$ and $w_{M} \in\left[0, \Pi_{M}\right]$ which "implement" the preferred level of $e$ and $r$, this will be a second-best optimal financial contract. The level of $u$ then adjusts to clear the market for workers. The market outcome is given by:

PROPOSITION 2: In a market equilibrium, incentives are high powered and set to encourage risk-taking. Specifically,

$$
\begin{aligned}
\hat{w}_{H} & =\frac{A(\rho)+B(\rho)(1-\alpha)}{\alpha+\beta(1-\alpha)} \\
\hat{w}_{M} & =\frac{\beta A(\rho)-\alpha B(\rho)}{\alpha+\beta(1-\alpha)}
\end{aligned}
$$

with effort and risk-taking choices being $e=$ $A(\rho)$ and $r=B(\rho)>0$.

The pernicious effect of bailouts is clear since bonuses are now structured to encourage socially wasteful risk-taking. This is because intermediaries do not internalize the cost of the bailout and $B(\rho)>0$. As a consequence, we have $\hat{w}_{H}>\beta \hat{w}_{M}$. So incentives are too high powered compared to the socially optimal solution. This is the fundamental distortion in the structure of bonus pay induced by bailouts. Second, bailouts are also bad for effort incentives $(A(\rho)<A(0))$ leading to lower levels of effort put towards generating higher returns. This is because bailouts increase the return to failure. Bailouts also increase inequality since the benefits are shifted to financial sector workers who are already paid a rent to motivate them. 


\section{Optimal Taxation}

Suppose now that there is a proportional tax on levied on bonuses paid out by the financial sector with differential rates set for the high state, $t_{H}$, and the medium state $t_{M}$. We characterize the optimal taxes on bonuses by considering what would be needed to support the second-best optimum as described in Proposition 1 at the market equilibrium described in Proposition 2. Since $e=\sqrt{2 u}$, the optimal taxes on risk taking and effort respectively solve $B(\rho)=\beta t_{H} w_{H}-t_{M} w_{M}$ and $A(\rho)-\alpha t_{H} w_{H}-$ $(1-\alpha) t_{M} w_{M}=\frac{A(0)}{2-\lambda}$. These can be used to solve for $\left\{t_{M}, t_{H}\right\}$ using the observation that $e=\alpha w_{H}+(1-\alpha) w_{M}$. This yields:

PROPOSITION 3: The optimal second-best tax scheme $\left\{t_{H}^{*}, t_{M}^{*}\right\}$ sets taxes as follows:

$$
t_{H}^{*}=\frac{A(\rho)-\frac{A(0)}{2-\lambda}+(1-\alpha) B(\rho)}{\frac{A(0)}{2-\lambda}}
$$

and

$$
t_{M}^{*}=\frac{\beta\left[A(\rho)-\frac{A(0)}{2-\lambda}\right]-\alpha B(\rho)}{\frac{A(0)}{2-\lambda}}
$$

where $t_{H}^{*}>t_{M}^{*} \geq \beta t_{H}^{*}$. The degree of tax progressivity as measured by $t_{H}^{*} / t_{M}^{*}$ is decreasing in $\lambda$.

Taxes do two things. First, they reflect distributional preferences as represented by $\lambda$. Second, they correct the distortion in effort and risktaking due to the bailout. Taxes on bonuses are decreasing in $\lambda$, i.e. as the distributional preference towards financial sector workers increases, there is a greater taxation of bonuses in both the high and the low state.

\section{Discussion}

While the massive bank bailouts in 2008 were headline grabbing, it is important to realize that modern states routinely protect investors from downside investment risk. Standard depositor protection in the retail banking sector is commonplace. However, the protective covenant of the state runs much deeper than this with a range of implicit or explicit guarantees on a variety of investment funds, such as private pensions or money market funds. Since the recent financial crisis began, there have been a range of explicit bailouts of the financial sector with banks and insurance companies receiving public injections of capital in a number of countries including the U.S., U.K., Ireland and Switzerland. All of these interventions subsidize the supply price of capital to the financial sector. The potential costs of such interventions could have added up to many trillions of dollars. Thus, it is hard to quantify the impact of these many implicit guarantees. However, Andrew B. Haldane (2010) suggests that the cost of bailouts in the UK is around $£ 20$ bn or around $1 \%$ of GDP and for the U.S., the figure is around $\$ 100 \mathrm{bn}$ which is also around $1 \%$ of GDP. While he acknowledges that these figures are imprecise, it is clear that the sums involved are significant. And this is without even recognizing that systems of social insurance and government transfer programs insulate citizens from the true consequences of their risky investment decisions.

Allowing citizens to invest in financial assets exposes them to a wide range of market risks. And there are sound reasons to think that it may be politically infeasible not to bailout investors when returns are low. This presents a classic Samaritan's dilemma problem of the kind first highlighted by James M. Buchanan (1975). It also seems improbable to believe that the financial sector can be regulated to completely remove excess risk taking once such guarantees are in place. We have shown that some form of bonus taxation in the financial sector is optimal above and beyond standard progressive income taxation. Moreover, the status quo with government guarantees and no bonus taxation is both inefficient and inequitable. Hence, we have identified a form of taxation that we believe makes the market system both fairer and more efficient.

\section{REFERENCES}

[1] Bell, Brian and John Van Reenen [2010], "Bankers' Bonuses and Extreme Wage Inequality in the UK," CEP Special Report No. 21.

[2] Benabou, Roland and Jean Tirole, [2012], "Bonus Culture: Competitive Pay, Screening and Multitasking," unpublished typescript. 
[3] Besley, Timothy and Maitreesh Ghatak [2011], "Taxation and Regulation of Bonus Pay,” C.E.P.R. Discussion Paper No. 8532.

[4] Buchanan, James. M. [1975] "The Samaritan's dilemma," in Edmund S. Phelps (ed.), Altruism, morality and economic theory, New York: Russel Sage Foundation.

[5] Haldane, Andrew B., [2010], "The \$100 Billion Question," Comments at the Institute of Risk and Regulation, Hong Kong available on Bank of England web site.

[6] Lemieux, T., MacLeod, B. and D. Parent, [2009], "Performance Pay and Wage Inequality," Quarterly Journal of Economics, 104 (1), 1-49.

[7] Mirrlees, James A. [1971], "An Exploration in the Theory of Optimum Income Taxation," Review of Economic Studies, 38(2), 175-208.

[8] Rothschild, Casey and Florian Scheuer, [2011], "Optimal Taxation with RentSeeking," unpublished typescript, Stanford.

[9] Tirole, Jean [2006], The Theory of Corporate Finance, Princeton University Press: Princeton and Oxford.

\section{Appendix}

Proof of Proposition 1: Use $\frac{1}{2}\left[e^{2}+r^{2}\right]=$ $u$ to obtain $e=\sqrt{2 u-r^{2}}$. Plug this into the maximand to obtain that $\hat{S}(x, u)$ and differentiating with respect to $r$ yields $-\frac{A(0)}{\sqrt{2 u-r^{2}}} r+B(0)$. Clearly this is negative at $r=0$ since $B(0)<0$. Also, it is straightforward to check that the second-order condition is satisfied. Hence $r=0$ as claimed. Turning to $\max _{u}\{\hat{S}(0, u)+\lambda u\}$, the first-order condition is $\frac{A(0)}{\sqrt{2 u-r^{2}}}-2+\lambda=0$. It is clear upon inspection that the second-order condition with respect to $u$ is satisfied. Since at the optimum $r=0$, we get $u=\frac{1}{2}\left[\frac{A(0)}{2-\lambda}\right]^{2}$.In that case $e=\sqrt{2 u}=$ $\frac{A(0)}{2-\lambda}$ and we solve the optimum contract from (2) plugging in the values $r=0$ and $e=\frac{A(0)}{2-\lambda}$ derived above. We need to check that the PC does in fact bind at the optimum, as have assumed above. Suppose not. Then $\max _{e, r} e[A(0)-e]+$ $r[B(0)-r]$ yields $e=\frac{A(0)}{2}$ and $r=0$ (as $B(0)<0$ ). Given this, the financial sector worker's equilibrium expected payoff is $\frac{1}{2} e^{2}=\frac{1}{2}\left[\frac{A(0)}{2}\right]^{2}$ and $\hat{S}(0, u)=$ $\left[\frac{A(0)}{2}\right]^{2}-\rho$. Then, $\max _{u}\{\hat{S}(0, u)+\lambda u\}$ is increasing in $u$ and $u$ will therefore be raised to the point where the $\mathrm{PC}$ is binding.

Proof of Proposition 2: Substituting $e$ from the $\mathrm{PC}$, the objective is to maximize $\sqrt{2 u-r^{2}}\left[A(\rho)-\sqrt{2 u-r^{2}}\right]+$ $r[B(\rho)-r]$ by choice of $r$.The firstorder condition can be solved to obtain: $r=\sqrt{2 u /\left(1+\left(\frac{A(\rho)}{B(\rho)}\right)^{2}\right)}$. Using this, the values of $e, w_{H}$, and $w_{M}$ stated in Proposition 2 are obtained. Then the zero profit condition can be used to obtain $u=2\left[A(\rho)^{2}+B(\rho)^{2}\right]$ which can now be used to solve for $r$ and $e$. From this $w_{H}$ and $w_{M}$ can be backed out using (2). Finally, note that the expected payoff of the intermediary is decreasing in $u$ when the PC binds. Consider the case where the PC does not bind. In this case, the expected surplus is $e[A(x)-e]+r[B(x)-r]+x-\rho$ and maximizing it with respect to only the incentive constraints yields a value of $\frac{A(x)^{2}+B(x)^{2}}{4}+x-\rho$ which is positive by Assumption 1 (i). This ensures that there exists a positive level of $u$ that solves the competitive case where the PC binds.

Proof of Propositions 3: The optimum solves $\alpha w_{H}+(1-\alpha) w_{M}=\frac{A(0)}{2-\lambda}$ and $\beta w_{H}=w_{M}$. This yields $A(x)-\frac{A(0)}{2-\lambda}=$ $-(1-\alpha) w_{M}\left[t_{H}-t_{M}\right]+t_{H} \frac{A(0)}{2-\lambda}$, $\beta t_{H} w_{H}-t_{M} w_{M}=B(x) \stackrel{t_{H}}{=}$ $\beta w_{H}\left[t_{H}-t_{M}\right]$ and $w_{H}=\frac{1}{2-\lambda} \frac{A(0)}{\alpha+(1-\alpha) \beta}$ which imply the result. Moreover, $\frac{t_{H}}{t_{M}}=\frac{A(\rho)-\frac{A(0)}{2-\lambda}+(1-\alpha) B(\rho)}{\beta\left[A(\rho)-\frac{A(0)}{2-\lambda}\right]-\alpha B(\rho)}$ is decreasing in 